\title{
VINEGAR AS AN ANTIMICROBIALAGENT FOR CONTROL OF Candida spp. IN COMPLETE DENTURE WEARERS
}

\author{
Telma Maria Silva PINTOํ, Ana Christina Claro NEVES ${ }^{2}$, Mariella Vieira Pereira LEÃO ${ }^{3}$, Antonio Olavo Cardoso JORGE
}

1- MSc, PhD Student, Department of Dentistry, University of Taubaté, Taubaté, SP, Brazil.

2- MSc, PhD, Assistant Professor of Oral Maxillofacial Prosthodontics, Department of Dentistry, University of Taubaté, Taubaté, SP, Brazil.

3- MSc, PhD, Assistant Professor, of Microbiology and Immunology, Bioscience Basic Institute, University of Taubaté, Taubaté, SP, Brazil.

4- MSc, PhD, Chair Professor of Microbiology and Immunology, Dental School of São José dos Campos, São Paulo State University, São José dos Campos, SP, Brazil.

Correspondence address: Profa. Dra. Ana Christina Claro Neves - Rua Padre Faria Fialho, 318 Jd. Santa Cruz, $1208-580$ Taubaté, SP, Brasil. Phone: +55-12-3621-3046/+55-12-9111-4790. E-mail: claroana@ig.com.br

Received: March 16, 2008 - Modification: May 12, 2008 - Accepted: June 19, 2008

\begin{abstract}
$T_{\mathrm{h}}$

he use of denture is known to increase the carriage of Candida in healthy patients, and the proliferation of Candida albicans strains can be associated with denture-induced stomatitis. The aim of this study was to evaluate the use of vinegar as an antimicrobial agent for control of Candida spp. in complete upper denture wearers. Fifty-five patients were submitted to a detailed clinical interview and oral clinical examination, and were instructed to keep their dentures immersed in a $10 \%$ vinegar solution (pH less than 3 ) overnight for 45 days. Before and after the experimental period, saliva samples were collected for detection of Candida, counting of $\mathrm{cfu} / \mathrm{mL}$ and identification of species by phenotypical tests (germ tube formation, chlamidoconidia production, and carbohydrate fermentation and assimilation). The results were analyzed using Spearman's correlation and Student's t-test ( $\mathrm{p} \leq 0.05$ ). Candida yeasts were present in $87.3 \%$ of saliva samples before the treatment. A significant reduction was verified in CFU/mL counts of Candida after treatment. A positive correlation between Candida and denture stomatitis was verified, since the decrease of cfu/mL counts was correlated with a reduction in cases of denture stomatitis. Although it was not able to eliminate $C$. albicans, the immersion of the complete denture in $10 \%$ vinegar solution, during the night, reduced the amounts (cfu/mL) of Candida spp. in the saliva and the presence of denture stomatitis in the studied patients.
\end{abstract}

Key words: Candida. Candida albicans. Denture. vinegar.

\section{INTRODUCTION}

Although dentistry has developed new materials and techniques used in the rehabilitation of completely edentulous patients, mucosa-supported dentures still act as possible agents of tissue damages. The continuous use of dentures and the lack of regular monitoring provide the development of injuries ${ }^{11,19}$, stomatitis being the most frequently observed.

Denture-induced stomatitis is an inflammatory reaction of the denture-bearing mucosa that affects approximately $65 \%$ of complete upper denture wearers ${ }^{28}$ and is characterized by different degrees of erythema ${ }^{1,6,8,12}$. It has a multifactorial etiology, and C. albicans is reported as the primary etiologic agent ${ }^{1,21}$.

Poor hygiene of dentures is also associated with the disease $^{4}$, demonstrating the importance of denture cleansing by mechanical and/or chemical methods. The most commonly used mechanical methods are brushing with dentifrice or neutral soap and use of ultrasonic devices. The chemical methods involve denture immersion in chemical products, such as sodium perborate and sodium hypochlorite, hydrochloride, phosphoric and benzoic acids, chlorhexidine digluconate, and enzymes, like proteases and mutanases ${ }^{2,3}$.

Despite the large number of currently available commercial denture-cleansing products, less than $60 \%$ of the wearers make use of anyone ${ }^{4}$, possibly because of the low purchasing power of great part of the Brazilian population.

The vinegar is a sour and astringent liquid consisting mainly of acetic acid, resulting from the fermentation of an alcoholic beverage, mainly white and red wines. This is product is cheap, easily found in the market, and seems to have antimicrobial potential ${ }^{18,26,27,30}$. Estrela, et al. ${ }^{9}$ (2004) evaluated the use of vinegar as an irrigating solution and intracanal medicament in microbial elimination from dog's teeth with apical periodontitis. Microbe absence was observed in $40 \%$ of samples treated with vinegar. 
Basson, et al. ${ }^{2}$ (1992) showed the effectiveness of undiluted vinegar solutions in killing adherent microorganisms when used as disinfection agent for denture cleansing. In vitro experiments have already shown that low fungicidal doses of acetic acid induce programmed cell death in C. albican $^{22}$.

The aim of this study was to verify the effectiveness of a $10 \%$ vinegar solution in the control of Candida spp. in oral cavity of complete upper denture wearers, evaluating the presence of stomatitis and Candida yeast counts in saliva.

\section{MATERIAL AND METHODS}

After approval by the local Research Ethics Committee, 55 patients of both genders aged 32 to 81 years old, wearers of complete upper denture for more than 6 months, were invited to participate in this study. The patients informed the time of denture use. The exclusion criteria were: absence of yeasts in oral cavity, presence of diabetes mellitus, arterial hypertension or xerostomy, and use of antifungal, antibiotic and antidepressant drugs in the 6 months preceding the study. All the participants were informed about the study objectives and methodology and signed an informed consent form.

After detailed clinical interview, two previously calibrated examiners investigated the occurrence of stomatitis and other injuries on oral mucosa. Dentureinduced stomatitis, if present, was assessed according to Newton's classification, which is based on the clinical appearance of the inflamed mucosa under complete dentures: Type I: petechiae dispersed throughout all or any part of palatal mucosa in contact with the denture; Type II: diffuse erythema confined to the denture bearing area; and Type III: papillary hyperplasia with diffuse erythema confined to the denture bearing area ${ }^{20}$. The examiners also evaluated the hygiene of the dentures, considering it unsatisfactory when debris, biofilm accumulation or both were observed in any region of dentures.

After that, a sample ( 2 to $3 \mathrm{~mL}$ ) of non-stimulated saliva was collected from each patient, with the denture in place, using a disposable sterile collector. The samples were kept in ice and thermal bag during the transportation to the microbiology laboratory, respecting the period of $3 \mathrm{~h}$ between sample collection and processing.

Subjects were instructed to remove their denture at night (during approximately $8 \mathrm{~h}$ ), to brush the denture at least 3 times a day during $1 \mathrm{~min}$, after meals, using an appropriate toothbrush (Bitufe, Itupeva, SP, Brazil) and neutral coconut soap (Dias D’Ávila, Dias D’Ávila, Ba, Brazil) and, after that, to keep the denture immersed in $100 \mathrm{~mL}$ of a $10 \%$ vinegar solution $(\mathrm{pH}<3)$. The brushes, soap and vinegar solution were provided to patients by the authors. The solution was prepared using a red wine vinegar base (Minhoto, Raymundo da Fonte Group, Torres Galvão, Paulista, PE, Brazil) with $4 \%$ volatile acidity, which was diluted in sterile distilled water. The $\mathrm{pH}$ was measured using a pH meter (Micronal Ind. Ltd., Piracicaba, SP, Brazil), confirming an acidity of less than 3 . The vinegar solution was replaced for a fresh one daily. The experimental period had the duration of 45 days and after this time the patients were reexamined and new saliva sample was collected from each participant.

All saliva samples $(0.1 \mathrm{~mL})$ were plated in duplicate in Sabouraud Dextrose agar (Difco Laboratories, Detroit, MI, USA) added with chloramphenicol $(0.1 \mathrm{mg} / \mathrm{mL})$, and incubated at $37^{\circ} \mathrm{C}$ for $48 \mathrm{~h}$. After that, the number of colonies forming units per milliliter of saliva $(\mathrm{cfu} / \mathrm{mL})$ was counted. The presence of yeasts in suggestive colonies was confirmed after preparation of Gram-stained smears and observation under optical microscopy. Pure cultures in Sabouraud Dextrose agar were obtained from three different colonies of each morphology, which were identified by phenotypical tests $^{24}$, as follows: germ tube formation in sterile human sera; chlamidoconidia production in Corn Meal Agar (Difco) added with $1 \%$ Tween 80 (Interlab Distribuidora de Produtos Científicos S.A., São Paulo, SP, Brazil); sugar fermentation (glucose, galactose, sucrose, maltose and lactose) in phenol red broth (Difco) and sugar assimilation in chemically defined culture medium.

The data of the first collection were submitted to the Kruskal-Wallis test to evaluate if the time of denture use was related with the cfu/mL counts. Student's t-test was applied to verify the effect of the treatment in cfu/mL counts. Significance level was set at 5\%. Biostat statistical software (Bioestat, Goiânia, GO, Brazil) was used for both tests. In order to correlate the presence of stomatitis with the cfu/ $\mathrm{mL}$ counts, before and after the treatment, the data were submitted to Spearman's correlation using the SAS statistical software (Statistical Analysis System; SAS Institute Incorporation, Campus Drive Cary, NC, USA).

\section{RESULTS}

The 55 patients enrolled in this study had a mean age of $57 \pm 11.3$ years, and were using the complete upper denture for 6 months to 25 years (mean of 7.6 years). Yeasts of Candida genus were present in $48(87.3 \%)$ patients, from whom 62 isolates were obtained. Patients who showed no yeasts in the oral cavity were instructed to follow the treatment, but were excluded from the study.

Comparison between the mean of $\mathrm{cfu} / \mathrm{mL}$ of Candida yeasts, before and after the treatment, is shown in Table 1. The obtained $t$ value was positive $(t=8.91880)$, indicating a significant reduction in cfu/mL counts of Candida after the use of vinegar solution.

A reduction in the incidence of stomatitis was observed after the treatment of the dentures with the vinegar solution (Table 2). The correlation between the number of microorganisms and presence of stomatitis before and after the use of vinegar solution can be observed in Table 3. The results of Spearman's correlation demonstrated a positive correlation between the presence of Candida and denture stomatitis after the use of vinegar solution $(p<0.05)$, that is, the reduction of $\mathrm{cfu} / \mathrm{mL}$ counts was correlated with a reduction in the number of patients with denture stomatitis 
(34 before and 14 after the use of the vinegar solution). The age of the patients did not show any correlation with the number of Candida in saliva. Angular queilitis was present in 19 patients (34.6\%) before the treatment and this result did not change after the use of vinegar. Other injuries were not observed in studied patients.

In the second saliva collection, the number of Candida strains decreased by $29 \%$ (from 62 to 44). Before the treatment, 10 patients showed two species of Candida in saliva and 2 other patients showed an association of 3 species (Figure 1). After the treatment, only one patient showed association of 2 species (C. albicans and C. krusei). C. guilliermondii, $C$. lusitaniae and $C$. parapsilosis strains were absent after the use of vinegar solution. The isolated species, before and after vinegar use, are displayed in Table 4.

The Kruskal-Wallis test did not show significant difference between the mean $\mathrm{cfu} / \mathrm{mL}$ of the first collection and the time of denture use. The obtained results were: time of denture use between 0.5 and 3 years: mean cfu $/ \mathrm{mL}=$ 1063.3; between 4 and 8 years: mean $\mathrm{cfu} / \mathrm{mL}=1039.3$; between 9 and 15 years: mean cfu/mL $=1056.6$; and between 16 and 25 years: mean $\mathrm{cfu} / \mathrm{mL}=1073.7(\mathrm{p}=0.9107)$.

An important decrease in the number of patients with unsatisfactory hygiene after the use of vinegar was observed. Before the treatment, all 48 patients presented poorly cleaned dentures, and this number dropped to 8 after the use of vinegar.

TABLE 1- Mean of cfu/mL and standard deviation of Candida genus yeasts, before and after the use of vinegar solution (Student's t-test for paired samples)

\begin{tabular}{lcc}
\hline & $\begin{array}{l}\text { Before the use of } \\
\text { vinegar solution }(\mathbf{n = 4 8 )}\end{array}$ & $\begin{array}{l}\text { After the use of } \\
\text { vinegar solution }(\mathbf{n}=\mathbf{4 8})\end{array}$ \\
\hline Mean \pm Standard deviation & $1251.02 \pm 667.34$ & $451.25 \pm 380.19^{*}$ \\
Standard deviation of the difference & 621.27 & - \\
Mean of the differences & 799.77 & - \\
$t$ value & 8.9188 & - \\
\hline
\end{tabular}

*Statistically significant difference $(p \leq 0.05)$.

TABLE 2- Percentage of patients with or without denture-induced stomatitis, before and after the use of vinegar

\begin{tabular}{lccccc}
\hline & & Newton Classification & & Total & Total \\
& I & II & III & & \\
Before & $17(35.4 \%)$ & $14(29.16 \%)$ & $3(6.3 \%)$ & $34(70.8 \%)$ & $14(29.2 \%)$ \\
After & $19(39.6 \%)$ & $3(6.3 \%)$ & $1(2.1 \%)$ & $23(47.9 \%)$ & $25(52.1 \%)$ \\
\hline
\end{tabular}

TABLE 3- $p$ values of correlation between cfu/mL counts in saliva and presence of denture-induced stomatitis, before (BV) and after (AV) the treatment with vinegar (Spearman's correlation)

\begin{tabular}{lcccc}
\hline & $\begin{array}{c}\text { cfu/mL } \\
\text { BV }\end{array}$ & $\begin{array}{c}\text { cfu/mL } \\
\text { AV }\end{array}$ & $\begin{array}{c}\text { Denture stomatitis } \\
\text { BV }\end{array}$ & $\begin{array}{c}\text { Denture stomatitis } \\
\text { AV }\end{array}$ \\
\hline $\begin{array}{l}\text { cfu/mL } \\
\text { Before Vinegar (BV) } \\
\text { cfu/mL }\end{array}$ & - & 0.0078 & 0.5675 & 0.3334 \\
$\begin{array}{l}\text { After Vinegar (AV) } \\
\text { Denture stomatitis } \\
\text { Before Vinegar (BV) } \\
\begin{array}{l}\text { Denture stomatitis } \\
\text { After Vinegar (AV) }\end{array}\end{array}$ & 0.0078 & - & 0.1798 & 0.0442 \\
\hline
\end{tabular}

Statistically significant if $p \leq 0.05$. 
TABLE 4- Species of Candida genus isolated from oral cavity of 48 patients, before and after the use of vinegar solution

\begin{tabular}{lcccc}
\hline Species & \multicolumn{2}{c}{$\begin{array}{c}\text { Before the use of vinegar solution } \\
\text { Number of strains }\end{array}$} & $\%$ & \multicolumn{2}{c}{$\begin{array}{c}\text { After the use of vinegar solution } \\
\text { Number of strains }\end{array}$} \\
\hline C. albicans & 37 & 59.7 & 34 & 77.3 \\
C. glabrata & 8 & 12.9 & 3 & 6.8 \\
C. tropicalis & 6 & 9.7 & 4 & 9.1 \\
C. krusei & 6 & 9.7 & 3 & 6.8 \\
C. guilliermondii & 3 & 4.8 & - & - \\
C. lusitaniae & 1 & 1.6 & - & - \\
C. parapsilosis & 1 & 1.6 & 44 & - \\
Total & 62 & 100 & - & 100 \\
\hline
\end{tabular}

\begin{tabular}{|c|l|}
\hline Patients (n) & Associations of Candida Species \\
\hline 5 & C. albicans and C. glabrata \\
2 & C. albicans and C. krusei \\
1 & C. albicans and C. lusitaniae \\
1 & C. glabrata and C. guilliermondii \\
1 & C. krusei and C. tropicalis \\
1 & C. albicans, C. glabrata and C. tropicalis \\
1 & C. albicans, C. glabrata and C. parapsilosis \\
\hline
\end{tabular}

FIGURE 1- Associations of Candida species isolated from complete upper denture wearers, before the use of vinegar solution

\section{DISCUSSION}

In the present study, daily disinfection of complete dentures with vinegar for 45 days was undertaken and the number of Candida genus yeasts was analyzed. The evaluation of Candida in saliva was chosen to investigate whether denture cleaning and disinfection could change yeast counts in oral cavity, since the saliva reflects, in general, the whole oral microbiota. Another reason for this choice was the possibility to express the results per $\mathrm{mL}$, and thus to quantify the microorganisms using a more accurate method.

Although the use of the vinegar solution has reduced the Candida counts in the saliva of the patients, the high prevalence of $C$. albicans was still observed, being isolated 37 strains in the first saliva collection and 34 in the second one. Likewise, Geenwalt, et al. ${ }^{10}$ (1998), evaluated the antimicrobial action of a fermented drink (Kombucha) with a concentration of $7 \mathrm{~g} \mathrm{~L}-1$ of acetic acid and did not find an inhibitory action against $C$. albicans. It is likely that the acid $\mathrm{pH}$ favored the adherence of $C$. albicans to the denture acrylic and then to the mucosa ${ }^{15,17}$. Bernabé, et al. ${ }^{3}$ (2004) also verified no reduction in C. albicans counts using $0.5 \%$ of sodium hypochlorite and coconut soap as antimicrobial agents. However, as hypochlorite has an unpleasant smell and taste, the denture must to be properly washed to remove the product, and its continued use can produce stains on the denture surface, which did not occur with the use of $10 \%$ vinegar in the present study.

C. albicans is an opportunistic pathogen frequently isolated from oral cavity of denture wearers ${ }^{28}$, being considered the main etiological agent of the denture-induced stomatitis ${ }^{1,21}$, which is characterized by a pathological modification of the oral mucosa that covers the denture bearing tissues. It is more frequently found in patients wearing poorly cleaned and poorly fitted dentures for long periods ${ }^{4,25}$. The results of the present study showed the presence of denture-induced stomatitis in $70.8 \%$ of the studied population, confirming the high frequency of this disease in complete denture wearers.

Denture use can reduce the salivary flow, which interferes with the physiological cleaning function of the tongue and creates a favorable environment for microbial survival ${ }^{4}$. In addition to this, Candida cells seem to have affinity with denture acrylic ${ }^{23}$, favoring the adhesion of epithelial cells to the oral mucosa and the onset of denture stomatitis ${ }^{29}$. Denture use can thus be related to the presence of Candida, which can be associated with the severity of denture-induced stomatitis, as observed in this study. After use of vinegar solution, an expressive reduction in number of stomatitis cases was observed, mainly in patients with type II stomatitis, according to Newton classification.

When denture use is analyzed alone, C. albicans was the most common specie, representing $77 \%$ of the isolated microorganisms ${ }^{14}$. C. albicans was the most prevalent specie in this research, followed by $C$. glabrata, $C$. tropicalis, $C$. krusei, C. guilliermondii, and C. lusitaniae. Similar results have been reported by Davenport ${ }^{7}$ (1972) and McMullanVogel, et al. ${ }^{16}$ (1999), who had identified C. albicans in the saliva of $70 \%$ and $75 \%$ of complete denture wearers with stomatitis, respectively. However, in complete denture wearers who have more predisposing factors, many others species can be isolated ${ }^{13}$. The results of the present study demonstrated a higher prevalence of other Candida species before the use of vinegar (C. guilliermondii, C. lusitaniae and $C$. parapsilosis). Another interesting fact was the reduction in the number of associations with two and three species after the treatment.

A significant reduction in the number of patients with unsatisfactory denture hygiene after the treatment was 
observed in this study, demonstrating the efficiency of denture brushing followed by overnight immersion in the vinegar solution. Brushing associated with some kind of detergent, soap or dentifrice is the most frequently used method by removable denture wearers ${ }^{5}$. However, the effectiveness of brushing alone seems to be limited ${ }^{15}$, probably because of the existence of irregularities in the acrylic resins, which makes difficult the mechanical removal of microorganisms ${ }^{7,15}$. Therefore, in order to obtain highquality denture cleaning, brushing and immersion in chemical agents must be associated.

In spite of the development of new techniques and materials for complete denture cleaning, patient's lack of information, low purchasing power, reduced visual accuracy and the limited manual dexterity, which are common characteristics of elderly people, impair the indication of an efficient method for denture cleaning by prosthodontists. Although the vinegar solution was not able to eliminate $C$. albicans completely, it was effective in controlling other Candida species, since the counts of Candida spp. were reduced after the treatment.

The results of this study demonstrate that the search for new alternatives for the control of $C$. albicans in complete denture wearers should persist, since the $10 \%$ vinegar solution was not able to remove efficiently this yeast, which is the main etiological agent of denture-induced stomatitis.

\section{CONCLUSIONS}

The immersion of complete dentures in $10 \%$ vinegar solution, during the night, reduced the counts $(\mathrm{cfu} / \mathrm{mL})$ of Candida spp. in saliva and the presence of denture-induced stomatitis in the studied population.

\section{REFERENCES}

1- Arendorf TM, Walker DM. Oral candidal population in health and disease. Br Dent J. 1979;147(10):267-71.

2- Basson NJ, Quick AN, Thomas CJ. Household products as sanitizing agents in denture cleansing. J Dent Assoc S Afr. 1992;47(10):437-9.

3- Bernabé W, Mendonça-Neto T, Pimenta FC, Pegoraro LF, Scolaro JM. Efficacy of sodium hypoclorite and coconut soap used as disinfecting agents in the reduction of denture stomatitis, Streptococcus mutans and Candida albicans. J Oral Rehabil. 2004;31(5):453-9.

4- Budtz-Jörgensen E. Clinical aspects of Candida infection in denture wearers. J Am Dent Assoc. 1978;96(3):474-9.

5- Coelho CM, Sousa YT, Dare AM. Denture-related oral mucosal lesions in a Brazilian school of dentistry. J Oral Rehabil. 2004;31(2):135-9.

6- Cumming CG, Wight C, Blackwell CL, Wray D. Denture stomatitis in the elderly. Oral Microbiol Immunol. 1990;5(2):82-5.

7- Davenport JC. The denture surface. Br Dent J. 1972;133(3):101-5.

8- Dorocka-Bobkowska B, Budtz-Jörgensen E, Wloch S. Non-insulindependent diabetes mellittus as a risk factor denture stomatitis. J Oral Pathol Med. 1996;25(8):411- 5.
9- Estrela C, Holland R, Bernabé PFE, Souza V, Estrela CRA. Antimicrobial potential of medicaments used in healing process in dogs' teeth with apical periodontitis. Braz Dent J. 2004;15(3):181-5.

10- Greenwalt CJ, Ledford RA, Steinkraus KH. Determination and characterization of the antimicrobial activity of the fermented tea kombucha. Food Sci Technol Res. 1998;31(3):291-6.

11- Helft M, Cardash HS, Rones B, Ben-Ur Z. The prevalence of denture related injuries in patients resident at two Israeli geriatric hospitals. Gerodontoly. 1986;5(2):123-7.

12- Jeganathan S, Payne JA, Thean HP. Denture stomatitis in a elderly edentulous Asian population. J Oral Reabil. 1997;24(6):468-72.

13- Jorge AOC, Koga-Ito CY, Gonçalves CR, Fantinato V, Unterkircher $\mathrm{CS}$. Presence of Candida genus yeasts in the saliva of patients with different predisposing factors and of control individuals. Braz Dent Res. 1997;11(4):279-85.

14- Jorge J Jr, Almeida OP, Bozzo L, Scully C, Graner E. Oral mucosal health an disease in institucionalized elderly in Brazil. Community Dent Oral Epidemiol. 1991;19(3):173-5.

15- Kulak Y, Arikan A, Kazazoglu E. Existence of Candida albicans and microorganisms in denture stomatitis patients. J Oral Rehabil. 1997;24(10):788-90.

16- McMullan-Vogel CG, Jüde HD, Ollert MW, Vogel CW. Serotype distribution and secretory acid proteinase activity of Candida albicans isolated from the oral mucosa of patients with denture stomatitis. Oral Microbiol Immunol. 1999;14(3):183-9.

17- Monroy BT, Moreno-Maldonado V, Franco-Martinez F, Aldape-Barrios B, Quindos G, Sanchez-Vargas LO. Candida albicans, Staphylococcus aureus, Streptococcus mutans colonization in patients wearing dental prosthesis. Med Oral Patol Oral Cir Bucal. 2005;10(1):27-39.

18- Nascimento MS, Silva N, Catanozi MP, Silva KC. Effects of different disinfection treatment on the natural microbiota of lettuce. J Food Prot. 2003;66(9):1697-700.

19- Nevalainen MJ, Narhi TO, Ainamo A. Oral mucosal lesions and oral hygiene habits in the home-living elderly. J Oral Rehabil. 1997;24(5);332-

20- Newton AV. Denture sore mouth: a possible etiology. Br Dent J. 1962;112(9):357-60.

21- Nikawa H, Yamamoto T, Hamada T, Sadamori S, Agrawal S. Cleansing efficacy of commercial denture cleansers: ability to reduce Candida albicans biofilm activity. Int J Prosthodont. 1995;8(6):527-34.

22- Phillips AJ, Crowe JD, Ramsdale M. Ras pathway signaling accelerates programmed cell death in the pathogenic fungus Candida albicans. PNAS. 2006;103(3):726-31.

23- Samaranayake LP, McCourtie J, MacFarlane TW. Factors affecting the in vitro adherence of Candida albicans to acrylic surfaces. Arch Oral Biol. 1980;25(8-9):611-5.

24- Sandvén P. Laboratory identification and sensitivity testing of yeast isolated. Acta Odontol Scand. 1990;48(1):27-36.

25- Sherman RG, Prusinski L, Ravenel MC, Joralmon RA. Oral Candidosis. Quintessence Int. 2002;33(7):521-32.

26- Vijayakumar C, Wolf-Hall C. Evaluation of household sanitizers for reducing levels of Escherichia coli on iceberg lettuce. J Food Prot. 2002; 65(10):1646-50. 
27- Vijayakumar C, Wolf-hall C. Minimum bacteriostatic and bactericidal concentration of household sanitizers for Escherichia coli strains in tryptic soy broth. Food Microbiol. 2002;19(4):383-8.

28- Webb BC, Thomas CJ, Willcox MD, Harty DW, Knox KW. Candida associated denture stomatitis. A etiology and management: a review. Part 2. Oral diseases caused by Candida species. Aust Dent J. 1998;43(3):1606.

29- Webb BC, Willcox MD, Thomas CJ, Harty DW, Knox KW. The effect of sodium-hypochlorite on potencial pathogenic traits of Candida spp. Oral Microbiol Immunol. 1995;10(6):334-41.

30- Wu FM, Doyle MP, Beuchat LR, Wells JG, Mintz ED, Swaminathan B. Fate of Shigella sonnei on parsley and methods of disinfection. J Food Prot. 2000;63(5):568-72. 